\title{
Study on the Development Trend of Tourism in the Cloud under the Background of New Crown Epidemic
}

\author{
Hongyu Pan, Xuewei Yu \\ School of Architecture, Southwest University for Nationalities, Chengdu, China \\ Email:609055434@qq.com
}

How to cite this paper: Pan, H.Y. and Yu, X.W. (2020) Study on the Development Trend of Tourism in the Cloud under the Background of New Crown Epidemic. Open Access Library Journal, 7: e6658. https://doi.org/10.4236/oalib.1106658

Received: July 24, 2020

Accepted: August 17, 2020

Published: August 20, 2020

Copyright $\odot 2020$ by author(s) and Open Access Library Inc.

This work is licensed under the Creative Commons Attribution International License (CC BY 4.0).

http://creativecommons.org/licenses/by/4.0/ (c) (i) Open Access

\begin{abstract}
Under the influence of the new coronary pneumonia epidemic, the tourism development of various countries has been seriously impacted. This kind of force majeure factor causes the people's traveling style to change, does not leave the house to see the world becomes the traveling new situation, and "the cloud" traveling appears in the public view. In fact, before the epidemic, "cloud" tourism had already appeared in public life, but at that time, the "line and line" mode was the main, and the "cloud" tourism after the epidemic was simply "online" mode. Along with the development of the 5th G era, in the long run, "cloud" tourism will inevitably become one of the most important ways of tourism. It allows people to see the world at home while getting the experience. Based on the background of the new crown epidemic, this paper expounds the present situation of "cloud-based" tourism, and then analyzes the development trend of "cloud-based" tourism.
\end{abstract}

\section{Subject Areas}

Development Economics, Information Technologies

\section{Keywords}

New Crown Epidemic Situation, "Cloud” Tourism, Development Status, Development Trend

\section{Introduction}

"Cloud" tourism refers to a kind of online tourism with network and technology as the carrier. It is a brand-new home travel mode, which has injected new vitality into the development of tourism market. Under the background of the con- 
tinuous development of science and technology network, the tourism industry can realize the new mode of home-based tourism by integrating information resources and using high-tech means. Through "cloud" tourism, people can not only get the picture and text of the relevant tourist attractions, information and travel strategy, but also through the VR and AR of these two high-tech technologies to get the experience [1]. With the continuous development of new media, "cloud" tourism will certainly become a trend. Now through Weibo, WeChat and shake sound and other media to obtain relevant information of tourist destinations is also a "cloud" way of tourism. The digital development of the tourism industry is a trend to conform to the development of the times; the development of "cloud" tourism is conducive to promoting the transformation and upgrading of the tourism industry, and injects continuous vitality into the tourism industry.

In recent years, China's Spring Festival holiday tourism market scale gradually expanded. According to the China Tourism Research Institute, during the 2019 Spring Festival holiday, the total number of tourists received nationwide was 415 million; an increase of 7.6 percent over the same period last year tourism revenue was 513.9 billion yuan, up 8.2 percent from the same period last year. This set of data clearly shows that the Chinese tourism industry is in an upward period. But the sudden outbreak of the hot 2020 Spring Festival tourism season presses the pause button, and tourism industry losses. In this context, in view of the current situation of offline tourism market downturn, most scenic spots and museums use "cloud" tourism as a coping strategy.

\section{Current Situation of Tourism Development in the Cloud in the Context of Outbreak}

A sudden outbreak of the epidemic, "play to turn the Imperial Palace", "Yunyou Dunhuang", "Digital Qinling" and other "cloud" tourism IP have emerged. The Potala Palace was broadcast live for the first time in Taobao, with more than one million people watching in just one hour; the flying pigs launched 7500 live broadcasts in a row, with more than 30 million people watching ${ }^{1}$. It is not difficult to find that "cloud" tourism in the 2020 epidemic of the tuyere spewing out, its popularity is amazing. On the one hand, "cloud" tourism warms the cold winter period of tourism industry brought by the epidemic situation, the off-line market falls into the stall of the stop period, and "cloud" tourism brings a first line of vitality to the tourism industry in the special period through live broadcast. On the other hand, "cloud" tourism is also a new change in tourism. It is bringing a new experience of sightseeing [2].

\subsection{High Acceptance of "Cloud" Tourism}

In the context of the new coronary pneumonia epidemic, people's travel plans have been greatly affected. As a result of force majeure factors, the masses of

${ }^{1}$ Source of data: https://www.sohu.com/a/387706002_235941. 
tourism mode began to change, more willing to choose to stay home to see the world, so "cloud" tourism has also been developed. At this stage, "cloud" tourism is public welfare, in this special period, through network technology and other technologies to enable people to see the world at home, for the people's life added a lot of vitality and fun [3]. Through the "cloud" tourism, the masses can understand the characteristics and history of the relevant tourist attractions more deeply, and increase the interest of the masses, which is conducive to the development of offline tourism after the development. Many tourism platform organizations provide free "cloud" tourism, promote the promotion of this mode of tourism among the masses, promote the "cloud" tourism to become more acceptable to the masses, and lay a mass foundation for the development of "cloud" tourism.

\subsection{Diversified Forms of "Cloud" Tourism}

"Cloud" tourism refers to a kind of online tourism with network and technology as the carrier. With the continuous development of the network, technology and new media, the "cloud" tourism is becoming more and more diversified, such as it uses a variety of new media forms, such as Tik Tok, live broadcast platforms (such as Weibo, Taobao and Beili, etc.), and panoramic tours ${ }^{2}$. At this stage, the most important way of presenting "cloud" tourism is live broadcast with mass cloud tourism. People can be more involved in this journey by watching live broadcast and interactive communication [4]. With the support of AR and VR technology, virtual reality VR technology can create a real sense of presence through high-definition modeling and panoramic video, so that tourists can "visit" scenic spots anytime and anywhere, greatly reducing the cost of decision-making. And through realistic AR technology, tourists can obtain personalized, scene-based information and services anytime and anywhere, so that "cloud" tourism brings people the experience of reality [5]. As the $5 \mathrm{G}$ era comes, people can enjoy "cloud" travel whenever and wherever. This kind of tourism mode, which is not restricted by any conditions, will inevitably win the favor of the masses; this kind of multi-form tourism mode will inevitably bring more freshness to the masses.

\subsection{The Limitations of the Popularization Object of "Cloud" Tourism}

Today's "cloud" tourism promotion object is mainly to historical and cultural relatively strong cultural popular science places as the focus, such as museums, art galleries and science and technology museums, under certain conditions, the famous historical and cultural heritage sites and seasonal tourist attractions to promote [6]. This kind of tourism way will deepen the cultural background of the masses to a certain extent, let them have a deeper understanding of the rele-

${ }^{2}$ Panoramic tourism: panorama is originally a photographic term, used in tourism is to present all the scenic spots, generally using virtual reality and $3 \mathrm{D}$ of real scene two ways of presentation. 
vant tourist attractions, and promote the development of the integration of cultural tourism. But this kind of limited promotion method is not conducive to the propaganda and development of other scenic spots, only pay attention to the promotion of places with rich cultural heritage will gradually lose the new feeling of the masses. Each tourist attraction has its own reason and value of existence. We can through the "cloud" tourism this big data era of tourism, as comprehensive as possible to display valuable places in front of the masses, leading them to experience the experience.

\section{The Trend of Tourism Development in the Cloud}

Before the epidemic, "cloud" tourism has appeared, but at that time more as a channel, under the influence of the epidemic, through the innovation of technology and tourism mode, "cloud" tourism is realizing the transformation from channel to new tourism products. No longer just as an auxiliary means of offline tourism-simply show the environment of scenic spots, but through the deep excavation of scenic area culture, cultural activation, historical awakening, to create and offline unique experience products, through AR, 5G and other technologies to bring deeper and richer experience [7].

\subsection{Tourism in the Cloud Promotes the Deep Integration of Tourism Industry}

"Cloud" tourism is closely related to the development of China's live broadcast industry and high-tech, which can realize the transformation from "flow" to "retention". In recent years, webcast has become a new trend of China's economic development, and in the live broadcast plate, the tourism type of live broadcast is relatively small, the market prospect is huge. "Cloud" tourism with the help of AR technology for potential tourists provides more flexible travel information channels. "Cloud" tourism also breaks through the limitation of time and space, on the one hand, it slows down the actual reception pressure of popular scenic spots, on the other hand, it can also improve the popularization rate of Lengmen scenic spots. So that more tourists through the "cloud" tourism model to experience the cultural scenery of scenic spots to a greater extent, increase the breadth and depth of tourism so that tourism can develop in a deep, pluralistic and dynamic direction. "Cloud" tourism online to guide tourists, information feedback, for offline tourism publicity provides more diverse means to promote the development of the entire tourism industry.

\section{2. "Cloud" Tourism Will Become a New Mode of Innovation and Entrepreneurship}

"Cloud" tourism with live broadcast as the main means of support, compared with other industries relatively low threshold, through a mobile phone and a related professional knowledge rich, expressive anchor can be three-dimensional display of scenic spots to consumers. In this process, the anchorman sells the 
scenic spot tourism products in the form of carrying goods to make himself gain income, at the same time increase the exposure for the scenic spot, at the same time, it can also make the tourists obtain more comprehensive scenic spot information, and avoid the information asymmetry of offline tourism. Therefore, "cloud" tourism is a very innovative entrepreneurial model with development space.

\subsection{Tourism in the Cloud Promotes Industrial Integration}

"Cloud" tourism model, for many cultural attractions, museums and other places to bring Wenchuang products sales channels. On February 20, 2020, Tik Tok and nine museums in the United Nations "cloud tour"; on February 23, Taobao live broadcast and eight museums jointly launched "cloud spring tour" activities. Among them, Taobao live broadcast of the "Yunchun Tour" single day "live tourists" broken thousands, led Wenchuang products sold more than 1000 pieces [8]. Taobao believes that "Yunchun Tour" is not only to provide the process of watching the exhibition, but to build a whole long business night, including the organic combination of the business model and content derived from the museum and Taobao live broadcast platform, which not only helps to deepen the popularity of the museum, but also helps to further the prosperity of the cultural market.

\section{Summary}

Based on the analysis of the present situation, this paper studies the future development trend of cloud tourism, summarizes the present and looks forward to the future so as to correctly guide the development of new things. From now to the future, it is beneficial to its long-term development to analyze and study cloud tourism in a long-term perspective. Combined with the current social development background, this paper selects the latest "cloud" tourism data according to the actual development needs, and puts forward the achievable future development trend.

All in all, during the epidemic period, "cloud" tourism, as a tourism model in a special period, still has a lot of room for development in the future. It can not only promote the deep integration of online and offline, but also create unique tourism experience products. At the same time, it is a new tuyere of tourism development. For tourism, "cloud" tourism is its initiative to attack the market, in the VR, 5G and other representative of the frontier technology floor. "Cloud" tourism form will be more diverse. As the economic product of the special period, the study of cloud tourism is not comprehensive and in-depth, but only the present characteristics and future development trend are studied. The development of cloud-based tourism is good, but there are some problems in it. Only by studying the existing problems, finding out the countermeasures and putting forward a good development model can we realize the high-quality sustainable development of cloud-based tourism. 


\section{Conflicts of Interest}

The authors declare no conflicts of interest regarding the publication of this paper.

\section{References}

[1] Zhao, Y.H. (2020) Cloud Tourism as a Result of the Epidemic China Finance and Economics News. 2020-05-14(006).

[2] Liu, Z.Y., Ji, J.Y., Shang, B. and Li, C.Y. (2019) Current Situation and Trend of Intelligent Tourism. Enterprise Economy, 38, 68-73.

[3] Yu, J. (2020) Analysis on the Development Trend of Tourism Industry under the Background of "Internet". Tour Overview (Second Half Month), No. 1, 38-39.

[4] Chen, K.-Y. and Yang, S.-Y. (2019) A Cloud Information Monitoring and Recommendation Multi-Agent System with Friendly Interfaces for Tourism. Applied Sciences, 9, No. 20. https://doi.org/10.3390/app9204385

[5] Wu, X.A. (2020) Cloud Tourism Opens a New Form of Tourism. China Financial News, 2020-03-26(007).

[6] Yan, X.Q. (2020) Analysis of Trends in Tourism Development after the Epidemic. Human World, No. 7, 20-25.

[7] Lu, Y.H. (2020) Characteristics and Development Trend of Cloud Tourism. China Travel News, 2020-07-13(003).

[8] Zhang, C.L. (2020) Develop New Business Form. Cloud Tourism Hainan Daily, 2020-03-04(A07). 